service of competition and ambition, but it makes no explicit reference to the possibility that part of the explanation lies in human nature. There are many entertaining references to sex, but none to the reproductive imperative that makes sex so exceptionally interesting.

Still, this is a particularly good history for a scientist to read, devoting as it does much more time and effort to underlying material causes than has been traditional. It is an elegant, quick and engaging way to review what has happened in history, to learn much that is new, and to appreciate the past of the whole world, not just the West. It meets scientists almost halfway, trying to ground the events of history literally in the material facts of the planet. As Cook understands, the best and truest story of our experience on Earth is in part a scientific one. Clio, I think, is smiling.

Melvin Konner is in the Department of Anthropology, Emory University, Atlanta, Georgia 30322, USA. He is the author of The Tangled Wing: Biological Constraints on the Human Spirit, revised edition.

\section{Sowing seeds of discontent}

\section{So Shall We Reap}

by Colin Tudge

Allen Lane: 2003.380 pp. $£ 20$

\section{Anthony Trewavas}

A common method of political and religious persuasion is to dwell on the virtues of belief for the follower and damnation for the unbeliever. Science writer Colin Tudge uses the same approach in this book, which is devoted to what he calls 'enlightened agriculture'. The prospects for humanity "are somewhere between glorious and dire", we are told; glorious if you follow Tudge's proscriptions, hell if you don't. The book's subtitle hammers this home: "How everyone who is liable to be born in the next ten thousand years could eat very well indeed; and why, in practise, our immediate descendants are likely to be in serious trouble". And as if to emphasize the religious origin of such dichotomous futures for humans, the book is liberally spiced with biblical quotations.

Tudge regards food production as something that should be above the ordinary, grubby business of economics. He regards capitalism as acceptable provided it doesn't involve competition! He sees a future in which most of us return to the rustic idyll, happily tilling the land - although he does not say who will generate the cash to pay for education or health, or the other trinkets we have got used to and that people enjoy. Whether any of us want to return to that way

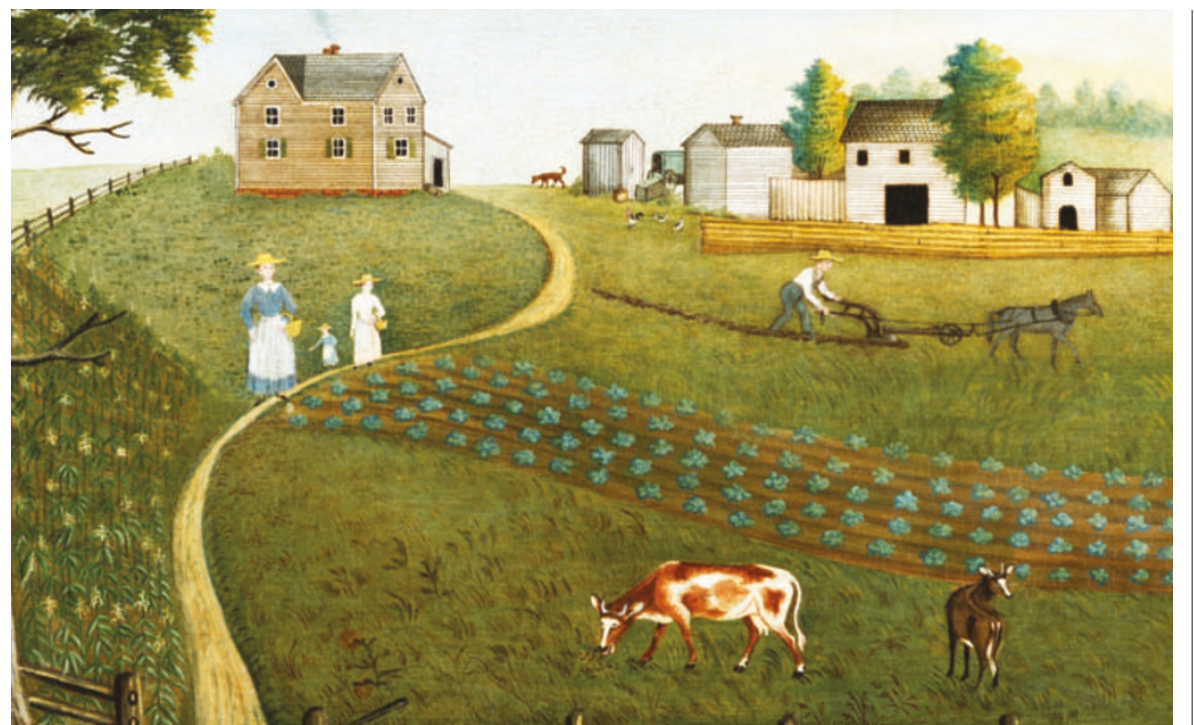

Cultivating a dream: do today's economic realities stop us returning to the rural idyll?

of life is not considered. And because it is generally agreed that there isn't much money to be made in farming, the prospects for most of us do not look good.

Antipathy to economics is common among those of Tudge's persuasion, but unless fine-sounding sentiments are properly underpinned with an understanding of economics, immense damage can result. It has been estimated that for every $1 \%$ increase in income, mortality is reduced by $0.05 \%$. The converse is equally the case. Scepticism about the motives of large global agribusiness is reasonable, but assuming that they are populated with shadowy figures out to control the world's food supply is not. Most UK citizens (probably including Tudge) invest heavily in the success of such enterprises through pensions and other financial plans. From Malthus onwards, the history of agricultural prediction has been a history of failure. Tudge's poorly based views will probably fare no better.

In Western countries a few decades ago, agricultural policy was simple. Production was all that was needed, and objective knowledge (science) was wheeled in to ensure its success. But abundance has produced new problems. Food security is no longer an issue, although rapid global cooling could quickly push it up the agenda. Instead, agriculture and, in Britain at least, the inevitable intermingling with the environment, have become contentious moral affairs. These are now areas of subjective knowledge in which disagreement, which merely reflects individual taste, is inevitable. Tudge claims that biology is the basis of his book, but chapters covering such issues as morality, aesthetics, genetically modified (GM) organisms, cash and values belie the claim.

It is a pity that authors such as Tudge and most environmentalists do not talk to farmers, as a more realistic appraisal might then surface. Farmers could tell them about responsible farming based on integrated management, conservation agriculture and animal-welfare principles, but also about the necessary business of running the farm at a profit. For the public, competition produces cheap fruit and vegetables, and by thus encouraging consumption has produced a healthier population with lower cancer rates. Tudge is more objective on organic farming and sees the regulations of this movement as dogma rather than common sense.

Tudge reserves his venom for GM crops, condemning the scientists who produce such "monstrosities" as obviously corrupt, as well as mad, bad and dangerous. I found this chapter to be a muddle of politics and naturalism, failing to adequately distinguish objective scientific knowledge from subjective assessments of Western agribusiness and nature.

Vitamin A deficiency in developing countries results in the premature death of about a million children a year and leaves another five million permanently blind. The primary reason for this situation, according to the World Health Organization, is poverty and ignorance about vitamins and diet. But Tudge claims instead that recent Western agricultural influences are the cause, as if these deficiencies did not happen in much earlier times. GM rice enriched with vitamin A to help counter this deficiency is a humanitarian scientific endeavour that demonstrates how valuable GM technology can be in improving life expectancy in the face of ignorance.

Tudge also fails to mention that both India and China now have proven examples of the benefits of GM crops to poor farmers. Herbicide-tolerant GM crops (produced by agribusiness) lead naturally to no-till agriculture, which has enormous environmental advantages over any kind of ploughed agriculture, including organic farming. These benefits are likewise not mentioned. GM 
food vaccines? Guess what. Not mentioned. The list of omissions is very long. In a pluralist society you do not ban useful products.

Mad? Bad? Dangerous? The only real danger is those who use subjective ideology to corrupt good objective sense.

Anthony Trewavas is at the Institute of Cell and Molecular Biology, University of Edinburgh, Mayfield Road, Edinburgh EH9 3JH, UK.

\section{The age-old problem of mortality}

\author{
The Biology of Death: Origins of \\ Mortality \\ by André Klarsfeld \& Frédéric Revah \\ (transl. Lydia Brady) \\ Cornell University Press: 2003. 204 pp. \\ $\$ 29.95$
}

\section{Caleb E. Finch}

The Biology of Death provides an engaging travelogue for ageing and death, from ancient mythology, the swamps of vitalism and the higher roads of the 'copernican revolution' of experimental gerontology, to today's Société de Thanatologie with its fixation on the ontology of death. The authors, André Klarsfeld and Frédéric Revah, are widely read and show fine taste in their choice of anecdote and historical detail. I was delighted to learn more about the French anatomist Xavier Bichat and the Chevalier de Lamarck. And I hadn't heard before the anecdote about Henry Ford searching junkyards to find parts of his Model $\mathrm{T}$ that never wore out.

The book's style and level of explanation are highly suitable for a general audience. The broad overview of gerontological fact, fiction and theory is basically sound and provides a useful introduction to the perplexities of biological ageing. However, despite the authors' scientific credentials as experimental neurobiologists, some misunderstandings have crept in that will irritate the informed. It is a pity that these were not picked up in review by experts in biogerontology before the publication of either the French edition (Janvier, 2000) or this English translation.

The authors repeat a once common misunderstanding about the Hayflick limit that is still transmitted by the popular press: "These cells stopped dividing and died after having performed a fairly constant number of around fifty divisions." Cellular gerontologists, including Leonard Hayflick, now agree that 'senescent' cultures of fibroblasts can persist in stationary, but metabolically active, states for many months or even years (as do most of our brain and heart cells). Moreover, clonal analysis of daughter cells shows huge differences in the number of subsequent divisions, which are anything

\section{Dress for DNA}

Molecular genetics has proved a rich source of imagery and ideas for contemporary artists, as the DNA sequence/spinal-column dress shown here attests. It forms part of the collection Primitive Streak, a collaboration between designer Helen Storey and her sister Kate, a research biologist. Their work, and that of other artists inspired by the genetic revolution, is the subject of The Molecular Gaze: Art in the Genetic Age (Cold Spring Harbor Laboratory Press, 2004) by artist Suzanne Anker and the late Dorothy Nelkin, a social scientist. Anker and Nelkin seek to place these images in context within the history of art and to provide insight into the social and cultural meaning of the genetic revolution through the gaze of artists. They explore themes including the meaning of mutation and the blurring of species boundaries.

Mary Purton but "fairly constant". The Hayflick limit therefore represents an ensemble average of very heterogeneous cell populations.

This intrinsic heterogeneity confounds interpretations of measurements made on extracts from millions of cells. For example, if gene A goes up and B goes down, relative to a younger stationary culture, it can not be known if A and B have changed in the same cell. The book also implies that the Hayflick limit can be used up during the lifespan. However, the doubling potential of skin fibroblasts does not alter as an adult ages.

The enormous variety of life histories and modes of death in different species of animals and plants intrigues the authors. They draw liberally from examples I collected over 30 years and mentioned in my own book Longevity, Senescence, and the Genome (University of Chicago Press, 1990), which they cite. I had hoped to find some mention of key examples that have since come to light, such as Justin Congdon's description of the negligible senescence of turtles. Dating of individual specimens of fish and other animals with radioisotopes has advanced far beyond the often uncertain counting of old growth rings (G. M. Cailliet et al. Exp. Gerontol. 36, 739-764; 2001). Deep-sea fish in several families in addition to the scorpeanids are now better documented to live beyond 100 years of age, including a gourmands' favourite, the orange roughy. But the anecdote about a 152-year-old sturgeon (Comm. Fish. Rev. 16, 28; 1954 - authors not named), cited without reference, should not have been repeated without a fisherman's wink or a scholar's note - this was a caveat that got away.

The authors' exposition of the evolutionary theory of genetic determinants of longevity is excellent. They provide a lucid review of the classic models of reproductive schedules, which address adaptive trade-offs between number of offspring, initial age of reproduction, reproductive senescence and age-group mortality, and give a basis for the evolutionary selection of lifespan. The authors then give a synthesis of more recent experimental work on fruitflies with field studies on both possums and guppies, which together show that predatory pressure can accelerate reproduction at the apparent expense of longevity. Curiously, though, they do not discuss genetics of longevity in human twins. Several twin studies have shown that lifespan has a relatively low heritability.

For a book on the biology of death it says little about the causes of death at advanced ages, which may be very different to those at younger 'old' ages. For example, for rats whose lifespan was extended by calorie restriction, autopsies revealed so little histopathology in $25 \%$ of rats that causes of death could not be assigned (I. Shimokawa et al. J. Gerontol. 48, B27-32; 1993). It may be that, as the number of very old humans increases, we see cases of death caused by systems failure from multiple small lesions, any one or several of which would not be a sufficient cause on its own. A systems thanatology could be modelled to represent synergies of different levels of dysfunction, with statistical estimates of fluctuations from the norm.

The Biology of Death belongs on the same shelf as other recent popular books on ageing, such as Hayflick's How and Why We Age, Steven Austad's Why We Age and Tom Kirkwood's Time of Our Lives. The remarkable progress being made throughout gerontology has provided scope for the frequent new accounts aimed at the general public.

Caleb Finch is at the Andrus Gerontology Center and Department of Biological Sciences, University of Southern California, Los Angeles, California 90089-0191, USA. 